\title{
Differential Virulence by Strains of Cucumber mosaic virus is Mediated by the $2 b$ Gene
}

\author{
Bu-Jun Shi, ${ }^{1,2}$ Peter Palukaitis, ${ }^{3}$ and Robert H. Symons ${ }^{1}$ \\ ${ }^{1}$ Department of Plant Science, Waite Institute, Adelaide University, Glen Osmond, SA, 5064, Australia; ${ }^{2}$ Department of \\ Molecular Bioscience, Adelaide University, North Terrace, Adelaide, 5005, Australia; ${ }^{3}$ Scottish Crop Research Institute, \\ Invergowrie, Dundee DD2 5DA, United Kingdom
}

Submitted 11 March 2002. Accepted 13 May 2002.

\begin{abstract}
The approximately 12-kDa $2 \mathrm{~b}$ protein, encoded by all cucumoviruses, had been shown to play an important role in viral long-distance movement, hypervirulence, and suppression of post-transcriptional gene silencing. The role of the $2 b$ gene in the hypervirulence of Cucumber mosaic virus (CMV) and whether hypervirulence was linked to movement were analyzed using a hybrid virus (CMV-qw), generated by replacing the $2 b$ gene in a subgroup II strain, Q-CMV, with the $2 b$ gene from a subgroup IA strain, WAII-CMV. CMV-qw was more virulent than Q-CMV or WAII-CMV on most of the host plant species tested. Northern blot and nucleotide sequence analyses demonstrated that CMV-qw was stably maintained during the course of infection and upon passage. Kinetic studies revealed that the hypervirulence induced by the hybrid virus was associated with neither increased viral RNA accumulation nor more rapid viral movement per se, suggesting that other functions of the $2 \mathrm{~b}$ protein are important in determining the hypervirulence.
\end{abstract}

Host range or pathogenicity differentiate strains of most viruses and, in many cases, these have been correlated with specific nucleotide sequence changes. Nevertheless, many nucleotide changes exist among strains of plant viruses that have not been correlated with differences in biological properties. In the case of strains and isolates of Cucumber mosaic virus (CMV), these differences in sequence have been used for taxonomic purposes and to attempt to correlate biological properties with such groupings (Anonymous 1998; Carrère et al. 1999; Daniels and Campbell 1992; Rodríquez-Alvarado et al. 1995; Varveri and Boutsika 1999; Wahyuni et al. 1992). CMV, the type member of the genus Cucumovirus, is one of the most widespread viruses known and infects over 1,000 species of plants (Edwardson and Christie 1991; Palukaitis et al. 1992). There are many strains and isolates of CMV, and earlier analyses suggested that these could be grouped into two subgroups, I and II, with about $75 \%$ overall nucleotide sequence identity between subgroups (Palukaitis et al. 1992). Some studies have suggested that subgroup I strains may, in general, be more virulent than subgroup II strains (Marrou et al. 1975; Wahyuni et al. 1992; Zhang et al. 1994) or may have differences in host range from subgroup II strains (Daniels and Campbell 1992; Marrou et al. 1975; Wahyuni et al. 1992). However, such correlations are less clear, because more recent phylogenetic anal-

Corresponding author: P. Palukaitis; Telephone: +44 1382 568523; Fax: +44 1382 568575; E-mail: ppaluk@ scri.sari.ac.uk yses of either RNA 2 (Hellwald and Glenewinkel 1999) or the gene encoding the capsid protein $(\mathrm{CP})$ have indicated that the strains and isolates can be grouped into three subgroups, designated IA, IB, and II (Roossinck et al. 1999), while phylogenetic analyses of each RNA, gene, or the entire genome indicate yet further subspeciation due to radial evolution (Haudenshield 2001; Roossinck 2002).

The genome of CMV contains a single-stranded, positivesense RNA divided into three segments, which contain five genes encoding proteins designated $1 \mathrm{a}, 2 \mathrm{a}, 2 \mathrm{~b}, 3 \mathrm{a}$, and $3 \mathrm{~b}$ (the CP) (Ding et al. 1994; Palukaitis et al. 1992). All five genes have been implicated in alterations in either host range or pathogenicity. The 1a and 2a proteins, encoded by RNAs 1 and 2 , respectively, are involved in RNA replication. The 3a protein and $\mathrm{CP}$ encoded by RNA 3 are functional in viral movement. The CP also is involved in RNA encapsidation, and is expressed from RNA 4, a subgenomic RNA derived from RNA 3 . The $2 b$ gene was identified more recently (Ding et al. 1994; Shi et al. 1997a). This gene is located at the $3^{\prime}$ end of RNA 2 and overlaps, but is out of frame with, the 3 'end of the $2 a$ gene. The $2 b$ gene encodes a protein ranging from 95 to 110 amino acids (aa) in different cucumoviruses and is expressed from RNA 4A, a subgenomic RNA derived from RNA 2 (Ding et al. 1994).

The $2 \mathrm{~b}$ proteins from CMV and the Cucumovirus Tomato aspermy virus (TAV) were shown to function as suppressors of post-transcriptional gene silencing (PTGS) (Brigneti et al. 1998; Li et al. 1999), and as determinants for viral long-distance movement (Ding et al. 1995a; Ji and Ding 2001). An interspecies hybrid virus, CMV-qt (Ding et al. 1996), in which the $2 b$ gene of subgroup II strain Q-CMV was replaced with that from the V-strain of TAV, was found to be much more virulent than the parental viruses (Q-CMV or TAV) in most of the host plant species tested (Ding et al. 1996). Moreover, the $2 \mathrm{~b}$ protein in the hybrid virus was shown to be the determinant of the hypervirulence (Ding et al. 1996). Thus, the difference in virulence observed previously between subgroup I and II strains of CMV (Marrou et al. 1975; Wahyuni et al. 1992; Zhang et al. 1994) also may be affected by differences in the respective $2 b$ proteins.

In this study, we constructed an intraspecies hybrid virus, CMV-qw, in which the $2 b$ gene of the Q-CMV was replaced with that of the subgroup IA strain WAII-CMV. The biological properties of CMV-qw were compared with those of the parental viruses and also CMV-qt, to establish the role of the $2 \mathrm{~b}$ protein in hypervirulence. In addition, the kinetics of viral RNA accumulation and virus movement were analyzed to establish whether these functions correlated with the differences in virulence. 


\section{RESULTS}

Infectivity and stability of the hybrid virus.

The structure of the insert in the biologically active plasmid pQCD2qw, in which the $2 b$ gene of Q-CMV has been replaced by the $2 b$ gene of WAII-CMV, is shown in Figure 1 . The position of insertion of the introduced $2 b$ gene from WAII-CMV allowed maintenance of the $2 \mathrm{a}$ open reading frame (ORF), although the C-terminus of the Q-CMV 2a protein would be replaced by the $\mathrm{C}$-terminus of the WAII-CMV $2 \mathrm{a}$ protein. The two predicted $2 \mathrm{~b}$ proteins differ by $44.6 \%$ in amino acid sequence (Shi et al. 1997a).

Coinoculation of the plasmid pQCD2qw with the biologically active plasmids pQCD1 and pQCD3 resulted in infection of Nicotiana tabacum by the intraspecies hybrid virus, CMV-qw, as did inoculation by the parental viruses. Northern blot hybridization analysis of the viral progeny RNAs from infected N. tabacum plants showed that all five RNAs of the virus (RNAs 1, 2, 3, 4, and 4A) were detected by the Conserved-40 probe (Fig. 2, lanes 4 and 7), which can detect all the CMV RNAs from either of the subgroups used here. The CMV-qw RNAs were similar in size to, but different in the ratios of accumulated RNAs from, those of Q-CMV (Fig. 2, lanes 2 and 5) or WAIICMV (Fig. 2, lanes 3 and 6), detected by the same probe. The relative levels of total RNA accumulation being compared here were extracted from equal weights of leaf tissue taken at 1 week post inoculation (p.i.). In this and other experiments, RNAs 3 and 4 of CMV-qw were detected only at very low levels, whereas the same RNAs of Q-CMV or WAII-CMV were detected as a much higher proportion of the total and encapsidated RNAs. These results suggest that the hybrid RNA 2 may have some trans-acting role in either the replication or the stability of RNAs 3 and 4 in the infected plants.

Using Probe $\gamma$, which is complementary to the sequence of the WAII-CMV 2b ORF (Shi et al. 1997a), only two RNAs, RNAs 2 and 4A of CMV-qw (Fig. 2, lanes 11 and 14) and QCMV (lanes 9 and 12), were detected in samples containing either total RNAs extracted from plants or purified virions, respectively. Similarly, only RNAs 2 and 4A of WAII-CMV, as well as various degradation products of RNA 2, were detected in the total plant RNA sample (lane 10). RNAs 2 and 4A of Q$\mathrm{CMV}$, as well as the various degradation products of both RNA $2 \mathrm{~s}$, were detected by Probe $\gamma$, because both the Q-CMV and WAII-CMV 2b ORFs share 65\% nucleotide sequence similarity. Thus, the WA-CMV $2 \mathrm{~b}$ gene and hybrid RNA 4A were encapsidated into virions of CMV-qw. By contrast, only RNA 2, but not RNA 4A, was detected in extracts from the virions of WAII-CMV isolated from $N$. tabacum by the Probe $\gamma$ (lane 13), and only RNAs 1 to 4, but not RNA 4A, were detected by the Conserved-40 probe (lane 6). This is because
Q-CMV RNA2

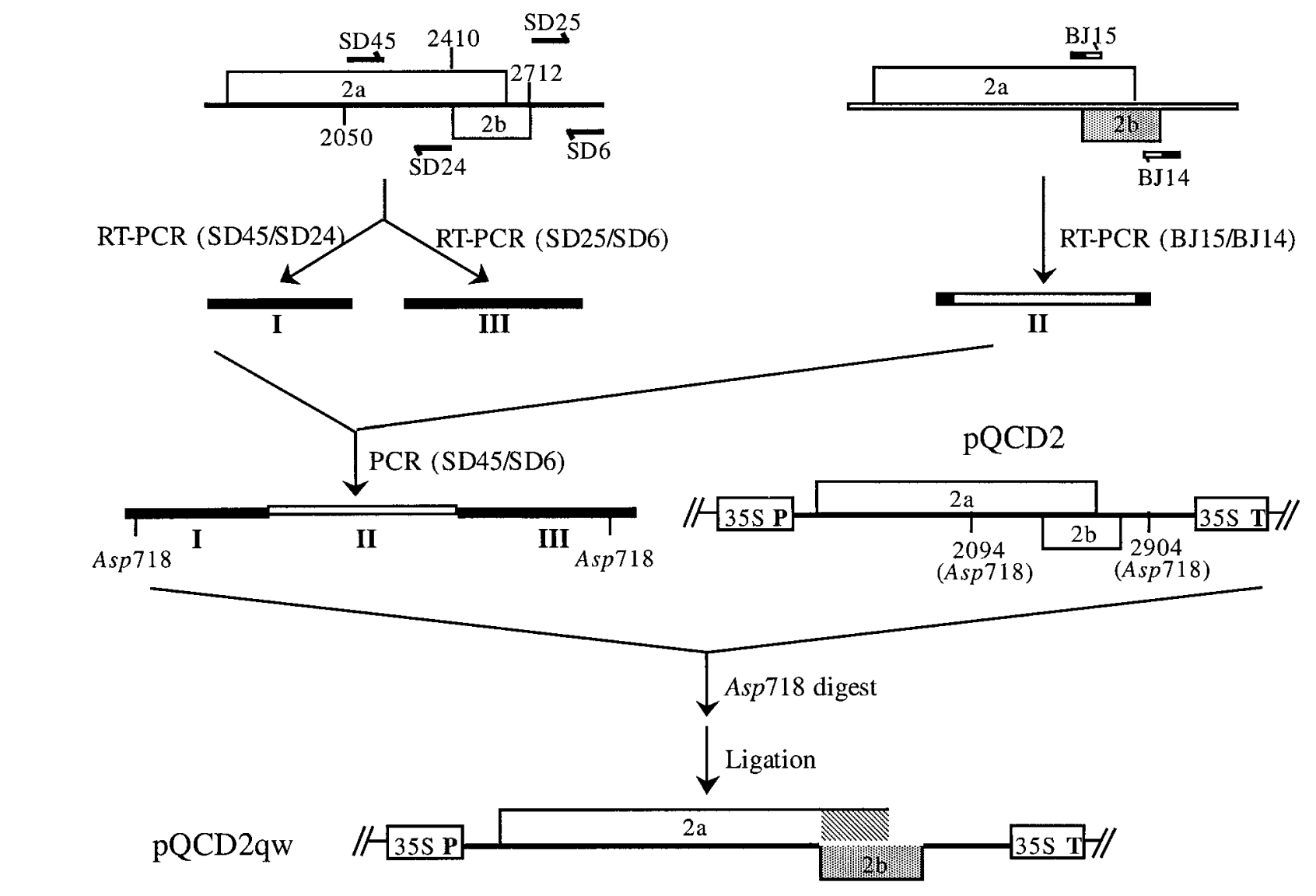

WAII-CMV RNA 2

Fig. 1. Schematic representation of the construct pQCD2qw and its generation. The 2b coding sequence in pQCD2, a cDNA clone of Cucumber mosaic virus (CMV) RNA 2, Q-strain, was replaced by the $2 \mathrm{~b}$ coding sequence from a cDNA clone of WAII-CMV RNA 2 . This was accomplished by mixing the polymerase chain reaction (PCR) products I and III from pQCD2 with the PCR product II from WAII-CMV RNA 2 and using the terminal primer pair SD45/SD6 and the PCR to produce a single fragment containing sequences of domains I, II, and III. This fragment was digested with the restriction enzyme Asp718 and ligated into pQCD2, previously digested with the same enzyme, to produce pQCD2qw. The open bars represent the Q-CMV RNA 2 sequence and the shaded bars represent the WAII-CMV 2b sequence. The cross-hatched area represents the sequence encoding the C-terminus of the WAII-CMV $2 \mathrm{a}$ protein replacing the corresponding sequence in the encoded Q-CMV 2 a protein, overlapping the $2 \mathrm{~b}$ open reading frame. 
RNA 4A is not encapsidated by WAII-CMV (Shi et al. 1997a). On the other hand, RNA 4A, containing a WAII-CMV 2b ORF and Q-CMV 5' and 3' nontranslated regions, can be encapsidated by the CP of Q-CMV (Fig. 2, lanes 7 and 14).

CMV-qw was passaged once through $N$. glutinosa and the RNA 4A of the purified CMV-qw, from both inoculated plants and passage plants, was characterized further by sequencing. No sequence variation was observed in any of the RNA 4As. In addition, the WAII-CMV $2 b$ gene was maintained in the same position as in the plasmid used for the initial inoculation (data not shown). Taken together, these results show that the intraspecies hybrid virus was biologically active and remained stable in infected N. glutinosa and N. tabacum plants.

\section{Virulence and host range comparison of the hybrid viruses.}

To compare the virulence of CMV-qw with that of Q-CMV and WAII-CMV on different plant species, the purified virions obtained from the second passage on $N$. glutinosa of each of these viruses were inoculated at the same concentrations onto nine plant species: Datura stramonium, Lycopersicon esculentum, N. clevelandii, N. glutinosa, N. tabacum, Physalis floridana (all in the family Solanaceae), Cucumis sativus (in the family Cucurbitaceae), Gomphrena globosa (in the family Amaranthaceae), and Stellaria media (in the family Caryophyllaceae). CMV-qt and TAV also were examined in the same experiments, as controls, because the interspecies virus CMV-qt was previously shown to be more virulent on several host species than either of its parental viruses (Ding et al. 1996). The infectivity and pathogenicity observed for each virus is summarized in Table 1. Except for TAV, each of the above viruses was able to infect the nine plant species. Of these viruses, CMV-qw and CMV-qt were the most virulent. They showed hypervirulence on most of the plant species tested. WAII-CMV showed either less virulence or virulence similar to that of CMV-qw on four and five of the host species tested, respectively. Q-CMV only caused mild systemic symptoms on all these plant species and was the least virulent on most of the plant species tested. However, on cucumber, the virulence of Q-CMV was similar to that of either CMV-qw or WAII-CMV. Such a difference in the virulence between Q-CMV and WAII-CMV further confirms previous observations that subgroup I strains are more virulent on some hosts than subgroup II strains (Marrou et al. 1975; Wahyuni et al. 1992; Zhang et al. 1994). CMV-qt only induced a localized mild mottle on cucumber, and no systemic infection. This, in combination with the fact that TAV did not even infect cucumber locally, indicates that the $2 b$ gene may also be a determinant of host specificity.

Although both CMV-qw and CMV-qt induced severe systemic symptoms (Table 1 and Fig. 3), the time required for the severe systemic symptoms to appear was different between these two viruses. Although CMV-qw induced severe systemic symptoms on the various plant species by 3 weeks p.i., (Fig. 3 and data not shown), CMV-qt induced symptoms of severity similar to those induced by CMV-qw on the same plant species, but by 5 to 7 days p.i. (data not shown). By 2 weeks p.i., CMVqw induced symptoms with severity similar to those induced by WAII-CMV (data not shown). These data suggest that the TAV $2 \mathrm{~b}$ protein expressed from CMV-qt may function more efficiently or more strongly as a virulence determinant than the WAII-CMV $2 \mathrm{~b}$ protein in CMV-qw, on their common hosts.

\section{Effect of hypervirulence on virus accumulation in the inoculated leaves.}

To determine whether time of appearance of symptoms and symptom severity were related to virus accumulation, two Nicotiana spp., N. tabacum and N. glutinosa, were inoculated with Q-CMV, WAII-CMV, CMV-qw, and CMV-qt. The accumulation kinetics of the progeny viral RNAs were determined by dot blot hybridization using the Conserved- 40 probe as described above. The results were quantified and are shown in Figures 4 and 5.

In the inoculated leaves of $N$. glutinosa, RNAs of all the viruses were detectable as early as 1 day p.i. (Fig. 4A). However, at this time point, and throughout the time course, RNA

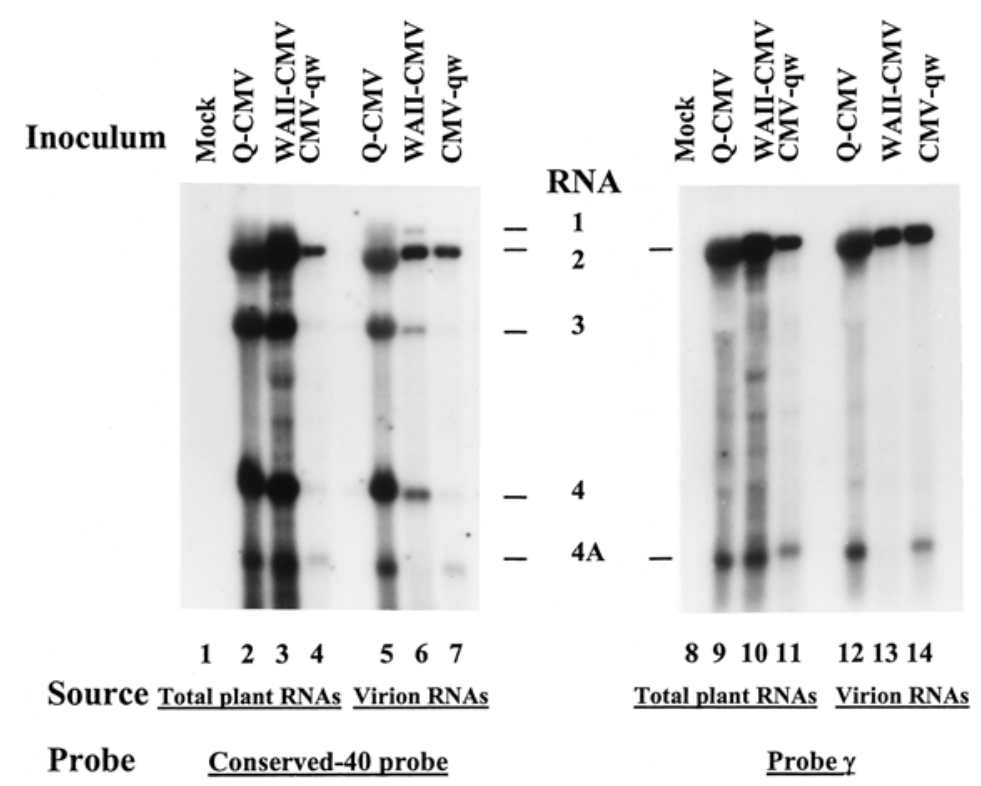

Fig. 2. Northern blot hybridization of the RNAs of Cucumber mosaic virus (CMV) Q-strain, WAII-CMV and the intraspecies hybrid virus CMV-qw. Nicotiana tabacum plants were inoculated with sterile water (lanes 1 and 8), Q-CMV (lanes 2 and 9), WAII-CMV (lanes 3 and 10), or CMV-qw (lanes 4 and 11). Equal amounts of leaf tissues were extracted and the RNAs were analyzed. RNAs from virions were purified from leaves infected by Q-CMV (lanes 5 and 12), WAII-CMV (lanes 6 and 13), or CMV-qw (lanes 7 and 14). The blots were hybridized either with the Conserved-40 probe (specific for the sequences in the $3^{\prime}$ end of all CMV RNAs), or with Probe $\gamma$ (specific for the $2 b$ gene) as described in text. The positions of viral RNAs $1,2,3$, 4 , and $4 \mathrm{~A}$ are indicated. Note that RNAs 1 and 2 of Q-CMV show differences in migration from RNAs 1 and 2 of the other viruses, and Q-CMV RNA 1 often is present at subliminal levels. 
accumulation levels for WAII-CMV and CMV-qw were higher than for those for Q-CMV and CMV-qt. At 3 and 5 days p.i., RNA accumulation levels increased exponentially for all the viruses, reaching maximum levels at 5 to 9 days p.i. for the various viruses. The RNAs of WAII-CMV accumulated to their maximum level at 5 days p.i., which was also the highest level for all the viruses during the time course of infection, and declined steeply thereafter. The RNAs of CMV-qt and Q-CMV accumulated to their maximum levels by 7 days p.i., while RNAs of CMV-qw accumulated to their maximum levels by 9 days p.i., at which time RNA accumulation levels were decreasing already for the other three viruses. From 11 to 17 days p.i., RNA accumulation level decreased only slightly for CMV-qw, but sharply for the other viruses. After 17 days p.i., RNA accumulation declined steeply for Q-CMV, WAII-CMV, and $\mathrm{CMV}$-qw. RNA accumulation of CMV-qt was recorded only to 17 day p.i. because, beyond this time, the inoculated leaves withered and were difficult to sample. Nevertheless, it is clear that the kinetics of accumulation of Q-CMV and CMV-qt in the inoculated leaves were identical up to 17 days p.i., while CMV-qt was much more virulent than Q-CMV in $N$. glutinosa (Table 1). By contrast, both WAII-CMV and CMVqw showed comparable kinetics of accumulation and virulence on N. glutinosa (Table 1 and Fig. 4A). Moreover, both WAIICMV and CMV-qw showed higher maximum levels of accumulation than Q-CMV or CMV-qt (Fig. 4A), while they were more virulent than $\mathrm{Q}-\mathrm{CMV}$ and less virulent than CMV-qt on this host (Table 1). Thus, there was no direct connection between levels of viral RNA accumulation in the inoculated leaves and virulence in this host.

In the inoculated leaves of $N$. tabacum, RNAs of all the viruses also were detectable at 1 day p.i., with steady increases in accumulation over the subsequent 8 to 10 days (Fig. 5A). RNAs of WAII-CMV and CMV-qw accumulated to their maximum level at 9 days p.i., whereas those of Q-CMV and CMV-qt accumulated to their maximum levels at 11 days p.i. After achieving their maximum levels, the RNA accumulation levels decreased sharply for all the viruses, similar to what were observed in the inoculated leaves of $N$. glutinosa (Fig. 5A versus Fig. 4A). The decrease in RNA levels may indicate turnover of viral RNA, or may simply reflect a cessation of viral RNA synthesis, while cells continue to elongate. Although WAII-CMV accumulated to slightly higher levels than the other three viruses in the inoculated leaves at many of the time points, it was less virulent on tobacco than either CMV-qt or CMV-qw (Table 1). By contrast, Q-CMV and CMV-qt again showed similar kinetics of accumulation in the inoculated leaves, but showed the most extreme differences in virulence. Thus, these results clearly indicate that the hypervirulence induced by the intraspecies hybrid virus is not associated with major differences in RNA accumulation in the inoculated leaves.

\section{Effect of hypervirulence on virus accumulation in the systemic leaves.}

To determine whether virulence was associated with a different rate or level of virus accumulation in the systemic leaves, the progeny viral RNAs were extracted from systemic leaves (the third leaf above the inoculated leaves) at 1-day intervals after inoculation until 3 day p.i., and then at 2-day intervals after inoculation until 25 day p.i. The RNAs were analyzed by dot blot hybridization using the Conserved- 40 probe. The results were quantified and are shown in Figures 4B and 5B.

In systemic leaves of $N$. glutinosa, no RNAs were detected for any of the viruses at 1 day p.i. (Fig. 4B). RNAs were detected at 2 days p.i., but only for WAII-CMV and CMV-qw, not for Q-CMV or CMV-qt. The latter two viruses were detectable at 3 days p.i. By 5 day p.i., RNAs of all the viruses accumulated to a readily detectable level, with slightly higher levels of WAII-CMV than for the other three viruses. By 7 days p.i., the RNAs of WAII-CMV had accumulated to a relatively high level, which was much higher than that achieved by the other viruses at any time point. All four viruses accumulated to their maximum levels by 9 days p.i. Thereafter, until 15 days p.i., RNA levels for WAII-CMV and Q-CMV decreased sharply while those for the two hybrid viruses decreased gradually. From 15 to 21 days p.i., there was a gradual decline in the levels of accumulation of all viruses and, after 21 day p.i., there was little further decrease in RNA accumulation for each virus. Thus, WAII-CMV accumulated more rapidly and to higher levels than CMV-qw in the systemic leaves of $N$. glutinosa (Fig. 4B), while both viruses induced similar virulence in this host (Table 1). This shows that there was no correlation between either the time of appearance of viral RNA, or the level of virus accumulation in the systemic leaves versus the level of virulence. This is supported by the accumulation kinetics of CMV-qt and Q-CMV in systemic leaves, which was very similar (Fig. 4B), while these two viruses showed the greatest differences in virulence (Table 1).

In systemic leaves of $N$. tabacum, the RNAs of WAII-CMV and CMV-qw were detected by 2 days p.i. and those of QCMV and CMV-qt were detected by 3 days p.i. (Fig. 5B). The RNAs of Q-CMV accumulated more rapidly and reached a maximum level of accumulation earlier than was observed for

Table 1. Virulence of viruses in various plant species ${ }^{\mathrm{a}}$

\begin{tabular}{|c|c|c|c|c|c|}
\hline \multirow[b]{2}{*}{ Plant species } & \multicolumn{5}{|c|}{ Virus species } \\
\hline & WAII-CMV & Q-CMV & CMV-qw & CMV-qt & V-TAV \\
\hline Nicotiana tabacum ${ }^{\mathrm{b}}$ & +++ & + & ++++ & ++++ & ++ \\
\hline N. glutinosa $a^{\mathrm{b}}$ & +++ & ++ & +++ & ++++ & ++ \\
\hline N. clevelandii ${ }^{\mathrm{b}}$ & ++ & + & +++ & ++++ & ++ \\
\hline Datura stramonium ${ }^{\mathrm{b}}$ & + & + & +++ & ++++ & + \\
\hline Lycopersicon esculentum $^{\mathrm{b}}$ & +++ & + & +++ & ++++ & ++ \\
\hline Physalis floridana ${ }^{\mathrm{b}}$ & +++ & + & ++++ & ++++ & ++ \\
\hline Stellaria media & +++ & + & +++ & ++++ & + \\
\hline Gomphrena globosa ${ }^{\mathrm{d}}$ & + & + & + & +++ & + \\
\hline Cucumis sativus ${ }^{\mathrm{e}}$ & ++ & ++ & ++ & $\mathrm{L}$ & NI \\
\hline
\end{tabular}

${ }^{\mathrm{a}} \mathrm{CMV}=$ Cucumber mosaic virus and TAV $=$ Tomato aspermy virus. Four levels of virulence were scored: $+=$ systemic infection but very mild to no systemic symptoms; ++ = systemic symptoms; +++ = severe systemic symptoms with leaf distortion; ++++ = severe systemic symptoms with leaf distortion and stunting; $\mathrm{L}=$ local infection only; and $\mathrm{NI}=$ no infection.

b Species in the family Solanaceae.

c Species in the family Caryophyllaceae.

d Species in the family Amaranthaceae.

e Species in the family Cucurbitaceae. 
the other viruses. This maximum level of accumulation of the Q-CMV RNAs was similar to that of CMV-qt, although the accumulation of the CMV-qt RNAs was delayed by 6 to 8 days (Fig. 5B). The RNAs of WAII-CMV and CMV-qw showed similar kinetics of accumulation to each other, reaching similar maximum levels of accumulation later than for Q-CMV, but earlier than for CMV-qt. After achieving their maximum levels, the accumulation kinetics of each virus decreased, eventually reaching steady-state levels between 17 and 19 days p.i. Q-CMV showed more rapid RNA accumulation earlier than CMV-qt (Fig. 5B), but induced a much less virulent reaction on tobacco (Fig. 3); therefore, we can infer that there was no correlation between the rate of initial movement and subsequent RNA accumulation and the extent of virulence. Similarly, the comparable kinetics of accumulation of WAII-CMV and CMVqw, with maximum levels higher than observed for Q-CMV or CMV-qt (Fig, 5B), showed no correlation between levels of accumulation and the virulence induced on this host (Fig. 3). Taken together, these results indicate that the hypervirulence induced by the intraspecies hybrid virus is not associated with viral movement or accumulation in the systemic leaves.

\section{DISCUSSION}

In this study, we examined the questions of whether differences in virulence between subgroups of CMV could be attributed to their $2 b$ genes, and whether hypervirulence associated with the $2 b$ gene was manifested by increased rates of systemic infection or accumulation of viral RNAs. We constructed an intraspecies hybrid virus, CMV-qw, in which the $2 b$ gene of Q-CMV was precisely replaced with that of WAIICMV. We showed that CMV-qw infected a selection of the known host plant species of Q-CMV and WAII-CMV and induced more severe systemic symptoms than either parental virus in most of the plant species, with cucumber as a notable exception (Table 1). Previous studies have shown that a QCMV mutant not expressing any $2 b$ protein failed to invade the systemic leaves of cucumber (Ding et al. 1995a), whereas CMV-qw infected this plant species and produced systemic symptoms similar that that of Q-CMV or WAII-CMV (Table $1)$. Thus, clearly, the $2 b$ gene of WAII-CMV could substitute

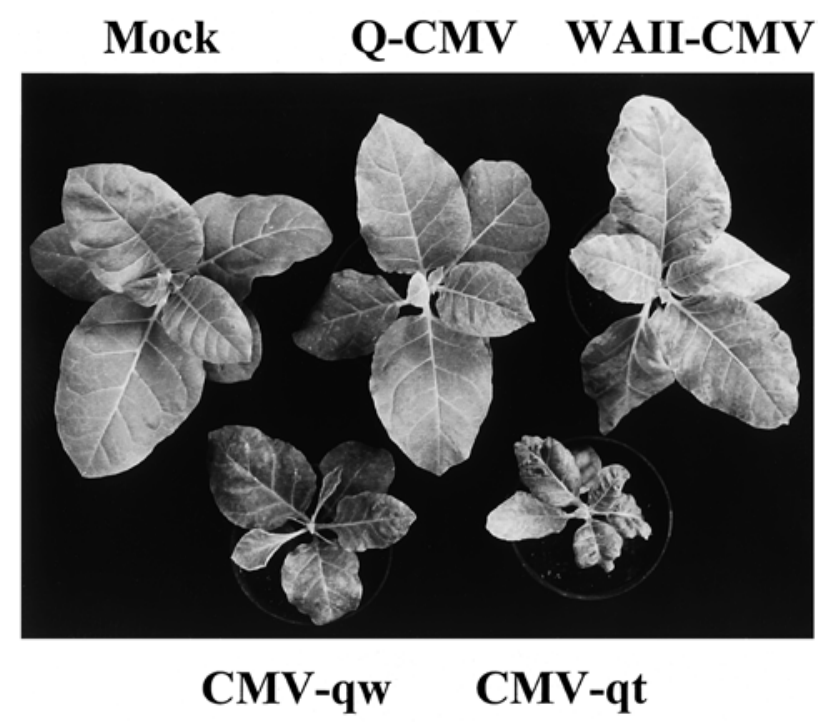

Fig. 3. Nicotiana tabacum cv. Samsun plants infected with Cucumber mosaic virus (CMV) Q-strain, WAII-CMV, the interspecies hybrid virus CMV-qt, and the intraspecies hybrid virus CMV-qw. The healthy $N$. tabacum plant used as a control was inoculated with sterile water. All the plants were photographed 3 weeks after inoculation. for certain functions of the $2 b$ gene of Q-CMV in the hybrid virus. This is not the case reported with a number of interspecies hybrid viruses, in which heterologous genes were only to some extent functional and did not function as efficiently as the analogous genes (Burgyan et al. 1993; De Jong and Ahlquist 1992; Hilf and Dawson 1993; Kuhn et al. 1996; Mise et al. 1993; Peng et al. 1995; Pletnev et al. 1992; Ryabov et al. 1999; Solovyev et al. 1996).

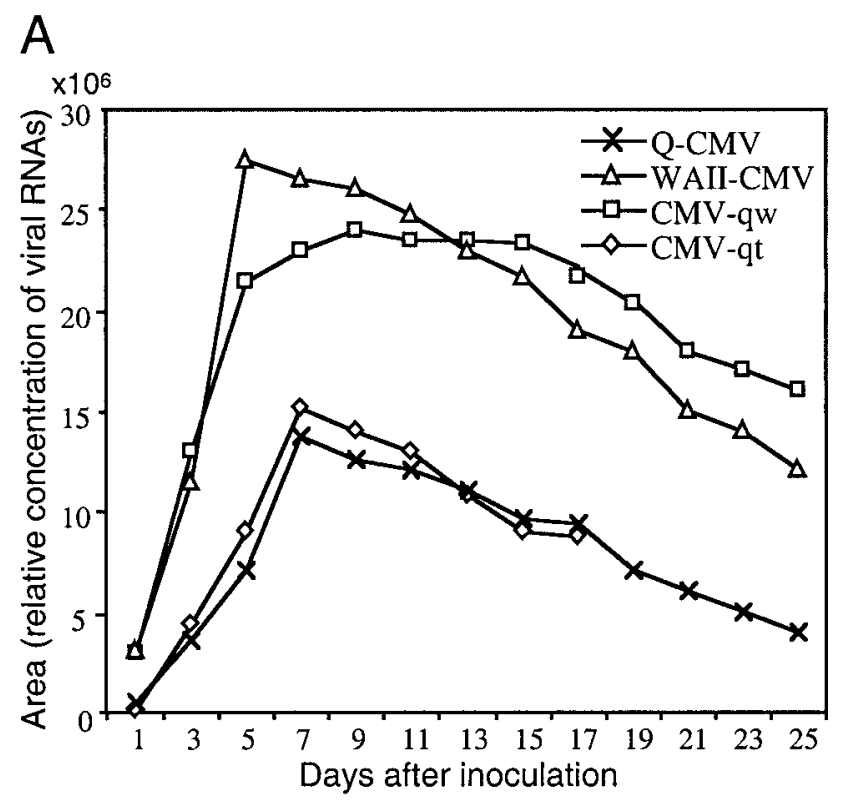

B

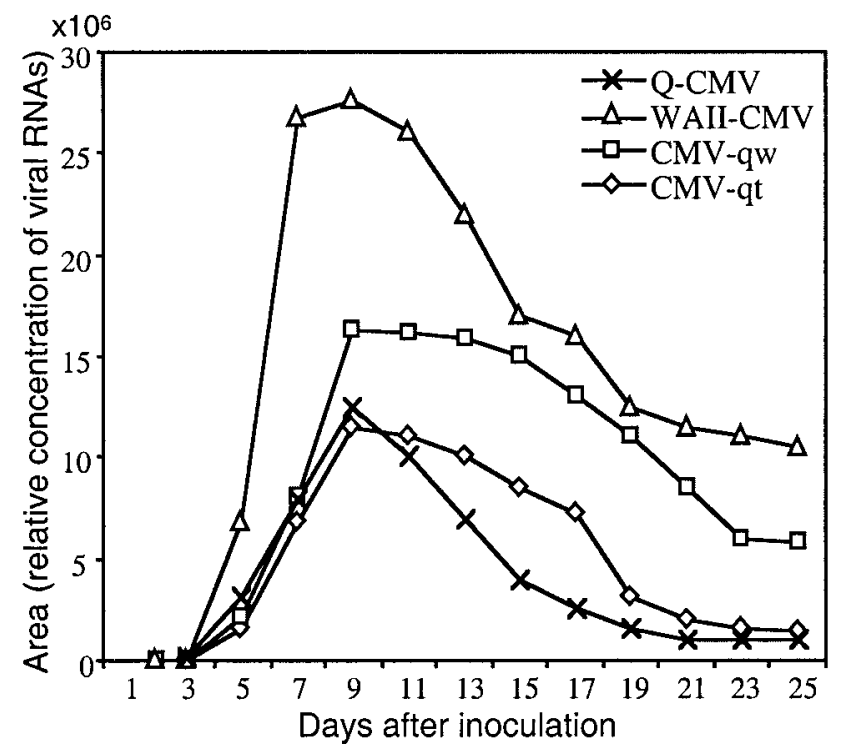

Fig. 4. Accumulation kinetics of Cucumber mosaic virus (CMV) Q-strain, WAII-CMV, and the two hybrid viruses, CMV-qt and CMV-qw, in Nicotiana glutinosa plants. Total plant RNA samples were taken from A, the inoculated leaves at 2-day intervals from 1 day until 25 days post inoculation (p.i.), and from B, systemically infected leaves at 1-day intervals from 1 to 3 days p.i. and at 2-day intervals from 3 to 25 days p.i. The RNA samples (corresponding to equal amounts of extracted RNAs) were applied to a nitrocellulose membrane and hybridized with the Conserved-40 probe as described in text. The hybridized filter was exposed to a phosphor screen and the amount of probe was quantified using a phosphorimager. The $y$-axis represents an integrated density of all the pixels in the spots (area) and also represents the relative concentration of viral RNAs. 
Is the $2 \mathrm{~b}$ protein a determinant of hypervirulence?

The replacement of the $2 b$ gene from Q-CMV with that of the highly virulent WAII strain significantly altered the low virulence of Q-CMV in most solanaceous species into a hybrid virus highly virulent to seven of the nine tested host species, including all six solanaceous species tested (Table 1). These results suggest that the low virulence of Q-CMV to solanaceous plants is associated with its $2 b$ gene and that differences in virulence to solanaceous plants between strains of CMV in subgroups IA and II (Marrou et al. 1975; Wahyuni et al. 1992; Zhang et al. 1994) may be determined by the $2 b$ gene. This
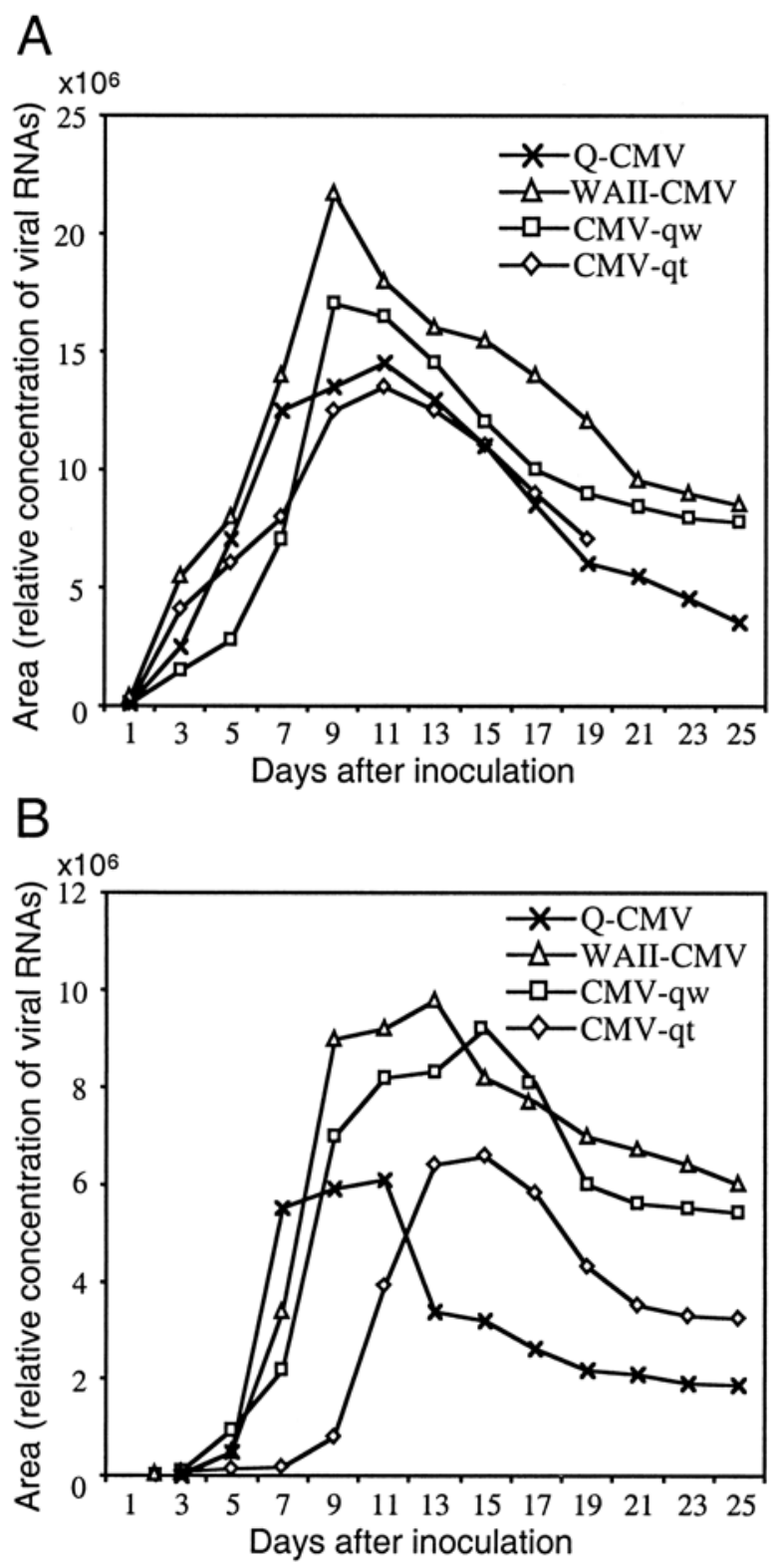

Fig. 5. Accumulation kinetics of Cucumber mosaic virus (CMV) Q-strain, WAII-CMV, and the two hybrid viruses, CMV-qt and CMV-qw, in Nicotiana tabacum cv. Samsun. Total plant RNA samples (corresponding to equal amounts of extracted RNAs) were taken from $\mathbf{A}$, the inoculated leaves at 2-day intervals from 1 day until 25 days post inoculation (p.i.), and $\mathbf{B}$, from systemically infected leaves at 1-day intervals from 1 to 3 days p.i. and at 2-day intervals from 3 to 25 days p.i. The RNA samples were applied to a nitrocellulose membrane and hybridized with the Conserved-40 probe as described in the text. The hybridized filter was exposed to a phosphor screen and the amount of probe was quantified using a phosphorimager. The $y$-axis represents an integrated density of all the pixels in the spots (area) and also represents the relative concentration of viral RNAs. suggestion is supported by the observation that replacement of the $2 b$ gene of Q-CMV with that of TAV, which is more virulent than Q-CMV on most solanaceous species, also resulted in hypervirulence in all inoculated solanaceous species (Ding et al. 1996). However, because the $3^{\prime}$ end of the 2 a ORF overlaps the $5^{\prime}$ end of the 2b ORF (Fig. 1), CMV-qw would express a 2a protein with the C-terminal 79 aa derived from the WAIICMV 2a protein. Thus, our experimental data do not allow us to exclude a role for the $\mathrm{C}$-terminal amino acids of the $2 \mathrm{a}$ protein in the hypervirulence. On the other hand, this seems unlikely, because previous studies have shown that the C-terminal sequences of the TAV $2 \mathrm{a}$ protein, encoded by the RNA sequences also encoding the TAV $2 b$ protein, did not play a role in the hypervirulence (Ding et al. 1996). Thus, it seems more likely that the hypervirulence is associated functionally with the $2 \mathrm{~b}$ protein.

It is not known how the $2 \mathrm{~b}$ protein determines the virulence of the virus. It has been suggested that the $2 \mathrm{~b}$ protein inhibits a number of host responses restricting infection by CMV, as it has been shown to affect salicylic acid-mediated defense against CMV (Ji and Ding 2001). There may be a spectrum of host responses and the WAII-CMV $2 b$ and TAV-2b proteins may either be more efficient at inhibiting these responses than the Q-CMV 2b protein, or inhibit a broader range of host responses. Alternatively, the hypervirulence may result from differences in the interaction between the heterologous $2 \mathrm{~b}$ protein and some component of Q-CMV in the absence of its own $2 b$, as has been suggested previously (Ding et al. 1996). The strength of this interaction would be expected to vary, depending on the origin of the components involved. However, it is not known whether the free (less interactive) or bound (more interactive) $2 \mathrm{~b}$ protein is involved in further interactions with the host; therefore, it is difficult to predict which would result in hypervirulence. Moreover, as the virulence in various host species infected by the same virus was different, a host-specific factor or factors also must be involved in the determination of the hypervirulence.

\section{The $2 \mathrm{~b}$ protein may also determine the host specificity of the virus.}

CMV-qw, Q-CMV, and WAII-CMV all infected cucumber systemically and induced severe systemic symptoms on this plant species (Table 1). However, CMV-qt did not infect cucumber systemically. CMV-qt only infected cucumber locally and induced very mild chlorotic spots on the inoculated leaves. A Q-CMV mutant not expressing a 2 b protein also did not infect cucumber systemically and induced only very mild chlorotic spots on the inoculated leaves (Ding et al. 1995a). Cucumber is a host for Q-CMV and WAII-CMV, but not for the V-strain of TAV (Habili and Francki 1974); therefore, these results suggest that the $2 \mathrm{~b}$ protein may function in a hostspecific manner and determine the host specificity of the virus. A similar situation has been described for the Tombusvirus Tomato bushy stunt virus (TBSV), in which the p19 protein was required for long-distance virus movement of TBSV in spinach and pepper, but not in $N$. benthamiana plants (Scholthof et al. 1995). Both the TBSV p19 and the CMV $2 \mathrm{~b}$ proteins are suppressors of PTGS (Brigneti et al. 1998; Voinnet et al. 1999); therefore, these two proteins may affect systemic movement simply by interfering with host responses blocking movement (Carrington 1999). Alternatively, the $2 \mathrm{~b}$ protein may form a specific transport-competent complex with host factors, which is necessary for viral long-distance movement. The formation of this complex may require a specific, viralencoded movement protein and host factors. The absence of $2 b$ protein or substitution with a $2 \mathrm{~b}$ protein unable to form such a complex in a given host may lead to host specificity. 
Neither rate nor level of virus accumulation determines hypervirulence.

In two other studies, it was suggested that a difference in the rate of virus accumulation was associated with hypervirulence (Ding et al. 1996; Gal-On et al. 1994). However, in this study, we found no correlation between the rates of RNA accumulation in either the inoculated leaves or the systemic leaves of two host species (Figs. 4 and 5) and the level of virulence (Table 1 and Fig. 3). Likewise, the maximum level of accumulation of CMV-qw RNAs was either similar to or slightly lower than that of the WAII-CMV RNAs, in both the inoculated and systemic leaves of the two Nicotiana spp. (Figs. 4 and 5), whereas CMV-qw was either similar to (Table 1) or more virulent than (Fig. 3) WAII-CMV. Accumulation of the CMV-qt RNAs also was generally lower than those of WAII-CMV and CMV-qw (Figs. 4 and 5), although CMV-qt was the most virulent of all the viruses (Table 1). Thus, the virulence also was not correlated with the levels of virus accumulation, whether early in the time course or at later times.

Although there is no specific correlation between the level of virulence and the rate of virus movement (Table 1 and Figs. $2-5$ ), some data do indeed suggest that the $2 b$ gene of WAIICMV may affect the rate of virus movement. In two hosts $(N$. tabacum and N. glutinosa), CMV-qw showed kinetics of accumulation more similar to those of WAII-CMV than those of QCMV (Figs. 4 and 5), with delays of 1 day or more observed in the detection of the RNAs of Q-CMV and CMV-qt. These data suggest that, at least in some hosts, the $2 \mathrm{~b}$ protein of WAIICMV may enhance either the rate or extent of systemic movement more efficiently than the $2 b$ proteins of Q-CMV or TAV in a Q-CMV context. Such differences in rates and extent of movement have been observed previously in different strains of CMV, and have been mapped to the 1a replication-associated protein (Gal-On et al. 1994), to specific amino acid changes in the 3a movement protein (Gal-On et al. 1996; Kaplan et al. 1997), or to specific amino acid changes in the CP (Wong et al. 1999). Moreover, transgenic expression of both the 1a (Canto and Palukaitis 1998, 2001) and 2a (Wintermantel et al. 1997; Wintermantel and Zaitlin 2000) replication-associated proteins also can affect systemic infection in tobacco; therefore, all of the CMV-encoded proteins appear to play some role in virus movement, demonstrating the complexity of this process.

\section{MATERIALS AND METHODS}

\section{Construction of the intraspecies hybrid clone.}

The intraspecies hybrid cDNA clone (pQCD2qw), a derivative of the full-length cDNA clone (pQCD2) of Q-CMV RNA 2 (Ding et al. 1995b), was constructed essentially as described for pQCD2qt (Ding et al. 1996). The three fragments I, II, and III (Fig. 1) were amplified by the polymerase chain reaction with primer pairs SD45/SD24, BJ15/BJ14, and SD25/SD6, respectively (primer sequences, Table 2). Primer pairs
SD45/SD24 and SD25/SD6 flank nucleotides 2050-2410 and nucleotides 2713-3035 of Q-CMV RNA 2, respectively, while primer pair BJ15/BJ14 flanks the WAII-CMV ORF $2 \mathrm{~b}$ sequence. The three amplified fragments then were mixed together and used as a template for a further amplification with primer pair SD45/SD6. The resultant fragment was digested with the restriction endonuclease Asp 718, and cloned into pQCD2 previously digested with the same enzyme, to produce pQCD2qw (Fig. 1). The $2 \mathrm{~b}$ sequence and adjacent regions in pQCD2qw were fully sequenced to ensure the plasmid contained the correct sequence.

\section{Plant inoculation and viral RNA analysis.}

pQCD2qw was co-inoculated with pQCD1 and pQCD3 onto either $N$. tabacum or $N$. glutinosa. pQCD1 and pQCD3 are the full-length cDNA clones of RNAs 1 and 3 of Q-CMV (Ding et al. 1995b). As controls, pQCD2 and an interspecies hybrid clone (pQCD2qt), in which the $2 b$ gene of Q-CMV was precisely replaced with that of TAV (Ding et al. 1996), were also individually co-inoculated with pQCD1 and pQCD3 onto the same plant species. All the clones inoculated were at an equal concentration of $10 \mu \mathrm{g}$ per $10 \mu \mathrm{l}$ per plasmid per plant. Virulence comparisons between CMV-qw, Q-CMV, WAII-CMV, and CMV-qt were carried out by inoculating the virions isolated from the above infected plants (each inoculum was at the concentration of $0.5 \mu \mathrm{g}$ per $10 \mu \mathrm{l}$ per plant) onto seedlings of D. stramonium, G. globosa, L. esculentum, P. floridana, S. media, N. tabacum cv. Samsun, N. glutinosa, N. clevelandii, and C. sativus cv. Green Gem, and scoring the symptom severity on the inoculated plant species (Ding et al. 1996).

Viral RNAs were extracted from the infected plants as described (Verwoerd et al. 1989). Northern blot hybridization analysis of the viral RNAs was carried out according to Shi and associates (1997b). Two riboprobes were used in the hybridization: the Conserved-40 probe, containing a sequence (5'-ACUGACCAUUUUAGCCGUAAGCUGGAUGGACAACCCGUUC- $3^{\prime}$ ) complementary to a conserved sequence present in the $3^{\prime}$ terminal region of each genomic RNAs in all cucumoviruses (McGarvey et al. 1995), and Probe $\gamma$, complementary to $240 \mathrm{nt}$ of the $2 b$ gene of WAII-CMV (Shi et al. 1997a). Purification of RNA 4A from the intraspecies hybrid virus CMV-qw was performed by polyacrylamide gel electrophoresis and elution (Peden and Symons 1973). Direct sequencing of the RNA 4A was performed as described by Fichot and Girard (1990).

\section{Time course of viral accumulation and movement.}

Two plant species, N. tabacum cv. Samsun and N. glutinosa, were chosen and inoculated with virions of Q-CMV, WAIICMV, CMV-qw, or CMV-qt at a concentration of $0.5 \mu$ g per 10 $\mu l$ per plant. For each time point, the inoculated leaves were removed from each of five plants, for both of the two plant species, at 2-day intervals, from 1 day p.i. until 25 days p.i. The systemic leaves (third above inoculated leaf) also were re-

Table 2. Primers used for generating the chimeric cDNA clone $\mathrm{pQCD} 2 \mathrm{qw}$

\begin{tabular}{lll}
\hline Primer $^{\mathbf{a}}$ & \multicolumn{1}{c}{ Primer sequence } & Primer position \\
\hline SD6 & 5'ACGGATCCTGGTCTCCTTATGGAGAACCTGTGG-3' & $Q-C M V R N A 2(3011-3035)^{\mathrm{b}}$ \\
SD25 & 5'-GATTTCCGACCCTTCGTCGT-3' & Q-CMV RNA 2(2711-2730) \\
$B J 14^{\mathrm{c}}$ & 5'-AAGGGTCGGAAATCAGAAAGCACCTT-3' & $Q-C M V R N A 2(2712-2724)$ \\
BJ15 & S & Q-CMV RNA 2(2397-2409) \\
SD24 & 5'-AAGAAGAAGAAGAATGGAATTGAACGT-3' & $Q-C M V R N A 2(2388-2409)$ \\
SD45 & 5'-TCTTCTTCTTCTTAACGGTAGT-3' & Q-CMV RNA 2(2050-2075) \\
\hline
\end{tabular}

\footnotetext{
${ }^{a}$ Primer sequences in italics are complementary to RNA 2 while those in roman type correspond to RNA 2.

${ }^{\mathrm{b}}$ Nucleotide positions corresponding to the primers.

${ }^{c}$ Nucleotides 300 to 312 from the 3'-end of WAII-CMV RNA 2 are shown in bold.

${ }^{\mathrm{d}}$ Nucleotides 618 to 631 from the $3^{\prime}$-end of WAII-CMV RNA 2 are shown in bold.
} 
moved from each of five plants of each of the two plant species, at 1-day intervals from 1 to 3 days p.i. and then at 2-day intervals until 25 days p.i. Total plant RNAs were extracted from $0.25 \mathrm{~g}$ of each detached leaf and pooled for the five leaves sampled for each time point, after which the RNAs were concentrated to $20 \mu \mathrm{g} / \mathrm{ml}$. Samples $(5 \mu \mathrm{l})$ of these RNAs were dot blotted onto a nylon membrane (Amersham, Little Chalfont, U.K.) and analyzed by hybridization using the riboprobe Conserved-40 described above. The hybridized membrane was exposed to a storage phosphor screen (Molecular Dynamics, Sunnyvale, CA, U.S.A.) and the hybridization signal was quantified with a phosphorimager (Storm 860, Molecular Dynamics).

\section{ACKNOWLEDGMENTS}

We thank X. Li for excellent technical assistance. Work in Australia was supported by the Australian Research Council Special Research Center for Basic and Applied Plant Molecular Biology. Work in the United Kingdom was supported by a grant-in-aid from the Scottish Executive Environment and Rural Affairs Department.

\section{LITERATURE CITED}

Anonymous. 1998. Detection and biodiversity of cucumber mosaic cucumovirus. Conclusions from a ringtest of European Union Cost 823 (new technologies to improve phytodiagnosis). J. Plant Pathol. 80:133-149.

Brigneti, G., Voinnet, O., Li, W. X., Ji, L. H., Ding, S. W., and Baulcombe, D. C. 1998. Viral pathogenicity determinants are suppressors of transgene silencing in Nicotiana benthamiana. EMBO (Eur. Mol. Biol. Organ.) J. 17:6739-6746.

Burgyan, J., Tavazza, M., Dalmay, T., Lucioli, A., and Balazs, E. 1993. Consequences of gene transfer between distantly related tombusviruses. Gene 129:191-196.

Canto, T., and Palukaitis, P. 1998. Transgenically expressed cucumber mosaic virus RNA 1 simultaneously complements replication of cucumber mosaic virus RNAs 2 and 3 and confers resistance to systemic infection. Virology 250:325-336.

Canto, T., and Palukaitis, P. 2001. A cucumber mosaic virus (CMV) RNA 1 transgene mediates suppression of the homologous viral RNA 1 constitutively and prevents CMV entry into the phloem. J. Virol. 75:9114-9120.

Carrère, I., Tepfer, M., and Jacquemond, M. 1999. Recombinants of cucumber mosaic virus (CMV): Determinants of host range and symptomatology. Arch. Virol. 144:365-379.

Carrington, J. C. 1999. Reinventing plant virus movement. Trends Microbiol. 7:312-313.

Daniels, J, and Campbell, R. N. 1992. Characterization of cucumber mosaic virus isolates from California. Plant Dis. 76:1245-1250.

De Jong, W., and Ahlquist, P. 1992. A hybrid plant RNA virus made by transferring the noncapsid movement protein from a rod-shaped to an icosahedral virus is competent for systemic infection. Proc. Natl. Acad. Sci. U.S.A. 89:6808-6812.

Ding, S. W., Anderson, B. J., Haase, H. R., and Symons, R. H. 1994. New overlapping gene encoded by the cucumber mosaic virus genome. Virology 198:593-601.

Ding, S. W., Li, W. X., and Symons, R. H. 1995a. A novel naturally occurring hybrid gene encoded by a plant RNA virus facilitates long distance virus movement. EMBO (Eur. Mol. Biol. Organ.) J. 14:5762-5772.

Ding, S. W., Rathjen, J. P., Li, W. X., Swanson, R., Healy, H., and Symons, R. H. 1995b. Efficient infection from cDNA clones of cucumber mosaic cucumovirus RNAs in a new plasmid vector. J. Gen. Virol. 76:459-464

Ding, S. W., Shi, B. J., Li, W. X., and Symons, R. H. 1996. An interspecies hybrid RNA virus is significantly more virulent than either parental virus. Proc. Natl. Acad. Sci. U.S.A. 93:7470-7474.

Edwardson, J. R., and Christie, R. G. 1991. Cucumoviruses. Pages 293319 in: CRC Handbook of Viruses Infecting Legumes. J. R. Edwardson and R. G. Christie, eds. CRC Press, Boca Raton, FL, U.S.A..

Fichot, O., and Girard, M. 1990. An improved method for sequencing of RNA templates. Nucleic Acids Res. 18:6162.

Gal-On, A., Kaplan, I., Roossinck, M. J., and Palukaitis, P. 1994. The kinetics of infection of zucchini squash by cucumber mosaic virus indicate a function for RNA 1 in virus movement. Virology 205:280-289.

Gal-On, A., Kaplan, I. B., and Palukaitis, P. 1996. Characterization of cucumber mosaic virus. II. Identification of movement protein sequences that influence its accumulation and systemic infection in tobacco.
Virology 226:354-361.

Habili, N., and Francki, R. I. B. 1974. Comparative studies on tomato aspermy and cucumber mosaic viruses. III. Further studies on relationship and construction of a virus from parts of the two viral genomes. Virology 61:443-449.

Haudenshield, J. S. 2001. Barriers to plant virus movement and the influence of subspecies variation. Ph.D. dissertation. Cornell University, Ithaca, NY.

Hellwald, K.-H., and Glenewinkel, D. 1999. A new genotype within cucumber mosaic virus subgroup I: Molecular characterization of the polymerase encoding RNA 2 and its capability to overcome replicasemediated resistance. J. Phytopathol. 147:671-677.

Hilf, M. E., and Dawson, W. O. 1993. The tobamovirus capsid protein functions as a host-specific determinant of long-distance movement. Virology 193:106-114.

Ji, L.-H., and Ding, S.-W. 2001. The suppressor of transgene RNA silencing encoded by Cucumber mosaic virus interferes with salicylic acidmediated virus resistance. Mol. Plant-Microbe Interact. 14:715-724.

Kaplan, I. B., Gal-On, A., and Palukaitis, P. 1997. Characterization of cucumber mosaic virus. III. Localization of sequences in the movement protein controlling systemic infection in cucurbits. Virology 230:343349.

Kuhn, R. J., Griffin, D. E., Owen, K. E., Niesters, H. G. M., and Strauss, J. H. 1996. Chimeric sindbis-ross river viruses to study interactions between alphavirus nonstructural and structural regions. J. Virol. 70:79007909.

Li, H. W., Lucy, A. P., Guo, H. S., Li, W. X., Ji, L. H., Wong, S. M., and Ding, S. W. 1999. Strong host resistance targeted against a viral suppressor of the plant gene silencing defense mechanism. EMBO (Eur. Mol. Biol. Organ.) J. 18:2683-2691.

Marrou, L., Quiot, J. B., Marchoux, G., and Duteil, M. 1975. Caractérisation par le symptomatologie de quatorze souches du virus de la mosaïque du concombre et de deux autres cucumovirus: Tentative de classification. Meded. Fac. Landbouuwwet. Rijksuniv. Gent. 40:107-121.

McGarvey, P., Tousignant, M., Geletka, L., Cellini, F., and Kaper, J. M. 1995. The complete sequence of a cucumber mosaic virus from Ixora that is deficient in the replication of satellite RNAs. J. Gen. Virol. 76:2257-2270.

Mise, K., Allison, R. F., Janda, M., and Ahlquist, P. 1993. Bromovirus movement protein genes play a crucial role in host specificity. J. Virol. 67:2815-2823.

Palukaitis, P., Roossinck, M. J., Dietzgen, R. G., and Francki, R. I. B. 1992. Cucumber mosaic virus. Adv. Virus Res. 41:281-348.

Peden, K. W. C., and Symons, R. H. 1973. Cucumber mosaic virus contains a functionally divided genome. Virology 53:487-492.

Peng, D., Koetzner, C. A., McMahon, T., Zhu, Y., and Masters, P. S. 1995. Construction of murine coronavirus mutants containing interspecies chimeric nucleocapsid proteins. J. Virol. 69:5475-5484.

Pletnev, A. G., Bray, M., Huggins, J., and Lai, C. J. 1992. Construction and characterization of chimeric tick-borne encephalitis/dengue type 4 viruses. Proc. Natl. Acad. Sci. U.S.A. 89:10532-10536.

Rodríquez-Alvarado, G., Kurath, G., and Dodds, J. A. 1995. Heterogeneity in pepper isolates of cucumber mosaic virus. Plant Dis. 79:450-455.

Roossinck, M. J. 2002. Evolutionary history of Cucumber mosaic virus deduced by phylogenetic analyses. J. Virol. 76:3382-3387.

Roossinck, M. J., Zhang, L., and Hellwald, K.-H. 1999. Rearrangements in the $5^{\prime}$ nontranslated region and phylogenetic analyses of cucumber mosaic virus RNA 3 indicate radial evolution of three subgroups. J. Virol. 73:6752-6758.

Ryabov, E. V., Roberts, I. M., Palukaitis, P., and Taliansky, M. 1999. Hostspecific cell-to-cell and long-distance movements of cucumber mosaic virus are facilitated by the movement protein of groundnut rosette virus. Virology 260:98-108.

Scholthof, H. B., Scholthof, K. B. G., Kikkert, M., and Jackson, A. O. 1995. Tomato bushy stunt virus spread is regulated by two nested genes that function in cell-to-cell movement and host-dependent systemic invasion. Virology 213:425-438.

Shi, B. J., Ding, S. W., and Symons, R. H. 1997a. In vivo expression of an overlapping gene encoded by the cucumoviruses. J. Gen. Virol. 78:237241.

Shi, B. J., Ding, S. W., and Symons, R. H. 1997b. Two novel subgenomic RNAs derived from RNA 3 of tomato aspermy cucumovirus. J. Gen. Virol. 78:505-510.

Solovyev, A. G., Zelenina, D. A., Savenkov, E. I., Grdzelishvili, V. Z., Morozov, S. Y., Lesemann, D. E., Maiss, E., Casper, R., and Atabekov, J. G. 1996. Movement of a barley stripe mosaic virus chimera with a tobacco mosaic virus movement protein. Virology 217:435-441.

Varveri, C., and Boutsika, K. 1999. Characterization of cucumber mosaic cucumovirus isolates in Greece. Plant Pathol. 48:95-100.

Verwoerd, T. C., Dekker, B. M. M., and Hoekema, A. 1989. A small-scale 
procedure for the rapid isolation of plant RNAs. Nucleic Acids Res. 17:2362.

Voinnet, O., Pinto, Y. M., and Baulcombe, D. C. 1999. Suppression of gene silencing: A general strategy used by diverse DNA and RNA viruses of plants. Proc. Natl. Acad. Sci. U.S.A. 96:14147-14152.

Wahyuni, W. S., Dietzgen, R. G., Hanada, K., and Francki, R. I. B. 1992. Serological and biological variation between and within subgroup I and II strains of cucumber mosaic virus. Plant Pathol. 41:282-297.

Wintermantel, W. M., Banerjee, N., Oliver, J. C., Paolillo, D. J., and Zaitlin, M. 1997. Cucumber mosaic virus is restricted from entering minor veins in transgenic tobacco exhibiting replicase-mediated resis- tance. Virology 231:248-257.

Wintermantel, W. M., and Zaitlin, M. 2000. Transgenic translatability increases effectiveness of replicase-mediated resistance to Cuсumber mosaic virus. J. Gen. Virol. 81:587-595.

Wong, S.-M., Thio, S. S.-C., Shintaku, M. H., and Palukaitis, P. 1999. The rate of cell-to-cell movement in squash of cucumber mosaic virus is affected by sequences of the capsid protein. Mol. Plant-Microbe Interact. 12:628-632.

Zhang, L., Hanada, K., and Palukaitis, P. 1994. Mapping local and symptom determinants of cucumber mosaic cucumovirus in tobacco. J. Gen Virol. 75:3185-3191 